\title{
Scar heterogeneity on cardiovascular magnetic resonance as a predictor of appropriate implantable cardioverter defibrillator therapy
}

Hussein Rayatzadeh", Alex Tan¹, Raymond H Chan ${ }^{1}$, Shalin J Patel ${ }^{1}$, Thomas H Hauser ${ }^{1}$, Long Ngo ${ }^{1}$, Jaime L Shaw ${ }^{1}$, Susie N Hong ${ }^{1}$, Peter Zimetbaum ${ }^{1}$, Alfred E Buxton ${ }^{1}$, Mark E Josephson ${ }^{1}$, Warren J Manning ${ }^{1,2}$ and Reza Nezafat ${ }^{1,3^{*}}$

\begin{abstract}
Background: Despite the survival benefit of implantable-cardioverter-defibrillators (ICDs), the vast majority of patients receiving an ICD for primary prevention do not receive ICD therapy. We sought to assess the role of heterogeneous scar area (HSA) identified by late gadolinium enhancement cardiovascular magnetic resonance (LGE-CMR) in predicting appropriate ICD therapy for primary prevention of sudden cardiac death (SCD).
\end{abstract}

Methods: From September 2003 to March 2011, all patients who underwent primary prevention ICD implantation and had a pre-implantation LGE-CMR were identified. Scar size was determined using thresholds of 4 and 6 standard deviations (SD) above remote normal myocardium; HSA was defined using 3 different criteria; as the region between 2 SD and 4 SD (HSA 2 -4SD), between 2SD and 6SD (HSA2-6SD), and between 4SD and 6SD $\left(\mathrm{HSA}_{4-6 \mathrm{SD}}\right)$. The end-point was appropriate ICD therapy.

Results: Out of 40 total patients followed for $25 \pm 24$ months, 7 had appropriate ICD therapy. Scar size measured by different thresholds was similar in ICD therapy and non-ICD therapy groups ( $P=N S$ for all). However, HSA $-45 D$ and $\mathrm{HSA}_{4-6 S D}$ were significantly larger in the ICD therapy group $(P=0.001$ and $P=0.03$, respectively). In multivariable model $\mathrm{HSA}_{2-4 S \mathrm{D}}$ was the only significant independent predictor of ICD therapy $(\mathrm{HR}=1.08,95 \% \mathrm{Cl}$ : 1.00-1.16, $\mathrm{P}=0.04)$. Kaplan-Meier analysis showed that patients with greater $\mathrm{HSA}_{2-4 S \mathrm{D}}$ had a lower survival free of appropriate ICD therapy $(P=0.026)$.

Conclusions: In primary prevention ICD implantation, LGE-CMR HSA identifies patients with appropriate ICD therapy. If confirmed in larger series, HSA can be used for risk stratification in primary prevention of SCD.

Keywords: Cardiovascular magnetic resonance, Late gadolinium enhancement, Implantable cardioverter defibrillator, Scar heterogeneity

\section{Background}

Sudden cardiac death (SCD) accounts for $5.6-15 \%$ of annual mortality in the United States and industrialized countries [1] and is a major cause of mortality in patients with advanced heart failure and coronary heart disease. Implantable cardioverter-defibrillators (ICD) have been found to significantly reduce arrhythmic death in this population [2]. Based on the MADIT-II and

\footnotetext{
* Correspondence: rnezafat@bidmc.harvard.edu

'Department of Medicine, Boston, MA, USA

${ }^{3}$ Beth Israel Deaconess Medical Center, 330 Brookline Ave, Boston, MA 02215, USA

Full list of author information is available at the end of the article
}

SCD-HeFT trials [3], current guidelines recommend ICD implantation as a class I indication for primary prevention of SCD in patients with a left ventricular ejection fraction (LVEF) $\leq 30 \%$ as well as those with LVEF $\leq 35 \%$ that are New York Heart Association (NYHA) heart failure class II or III [4].

Current guidelines use LVEF as the major risk stratifier for primary prevention ICD implantation [4]. While efficacious, the majority of patients receiving an ICD for primary prevention do not utilize this expensive therapy [5]. On the other hand, many patients with an LVEF > 35\% may develop potentially lethal ventricular arrhythmias (e.g. ventricular tachycardia and ventricular fibrillation) and

\section{Biomed Central}


SCD. Thus, there has been a growing focus on risk stratifying the patients at risk of SCD and finding the major predictors of SCD that play a role either independently or in conjunction with LVEF [6-8].

Multiple mechanisms underlie ventricular arrhythmias. Much evidence suggests a link between ventricular scar and arrhythmogenicity [9-12]. Late gadolinium enhancement cardiovascular magnetic resonance (LGE-CMR) can accurately characterize areas of myocardial injury and scar $[13,14]$. In one study of patients with LV dysfunction, infarct tissue heterogeneity on LGE-CMR was the only significant predictor of inducible sustained monomorphic VT [15]. However, VT inducibility is a surrogate end-point and may not reflect clinical efficacy. In the present study, we sought to investigate the correlation between LGE-CMR tissue heterogeneity and the occurrence of appropriate ICD therapy.

\section{Methods}

\section{Study design and patient selection}

The Beth Israel Deaconess Medical Center clinical CMR database was queried to identify all patients undergoing ICD implantation for primary SCD prevention from September 2003 to March 2011 who also had a preimplantation CMR. Patients with ischemic and idiopathic non-ischemic cardiomyopathies were included. All patients with hypertrophic, inflammatory, infiltrative, and arrhythmogenic right ventricular cardiomyopathies were excluded. Patient demographics and clinical followup records from the hospital electronic medical records were reviewed.

The study was carried out with Beth Israel Deaconess Medical Center Institutional Review Board approval and written informed consent was waived. The authors had full access to the data and take responsibility for its integrity. All authors have read and agreed to the manuscript as written.

\section{Cardiovascular magnetic resonance}

CMR was performed on a Philips $1.5 \mathrm{~T}$ (Philips Medical Systems, Amsterdam, Netherlands) CMR scanner with a commercial 5-element cardiac-surface coil. Cine images were acquired in a contiguous LV short-axis orientation with an electrocardiography-gated, breath-hold, steadystate free-precession sequence with full LV coverage (8-mm slice thickness, 2-mm interslice gap, in-plane spatial resolution $2 \times 2 \mathrm{~mm}, 30 \mathrm{~ms}$ temporal resolution). LGE-CMR was performed 15 minutes after the intravenous administration of $0.2 \mathrm{mmol} / \mathrm{kg}$ gadoliniumDTPA (Magnevist; Schering, Berlin, Germany) with a 2dimensional breath-hold, segmented inversion-recovery sequence (inversion time optimized by the Look-Locker sequence [inversion time scout] to null normal myocardium) acquired in the same orientation (short-axis stack) as the cine images, with the following imaging parameters: 8-mm slice thickness, 2-mm interslice gap, repetition time (TR) $4.2 \mathrm{~ms}$, echo time (TE) $1.8 \mathrm{~ms}$, flip angle $20^{\circ}$, field of view $320 \times 320 \mathrm{~mm}^{2}$, matrix $160 \times 160$, and spatial resolution $2 \times 2 \mathrm{~mm}^{2}$. In 9 patients LGE was performed using a 3D phase sensitive inversion recovery sequence (PSIR) with the following imaging parameters $10-\mathrm{mm}$ slice thickness, 5-mm spacing between slices, TR $4.2 \mathrm{~ms}$, TE $1.8 \mathrm{~ms}$, flip angle $15^{\circ}$, field of view $320 \times 320 \mathrm{~mm}^{2}$, matrix size $176 \times 156$, and spatial resolution $1.8 \times 2.0 \mathrm{~mm}^{2}$.

\section{CMR analysis}

CMR analyses were performed with commercially available software (QMassMR version 7.1.0; MedisInc, Leiden, Netherlands). LV endocardial and epicardial borders on both cine and LGE images were measured by planimetry, with special care taken to exclude papillary muscles and the intertrabecular blood pool. Left and right ventricular volume, mass, and ejection fraction were measured from the cine short-axis images using standard techniques [16].

The LV short-axis stack of LGE images was first assessed visually for the presence of LGE by two independent, experienced readers and disagreements were adjudicated by a senior observer. The readers were blinded to the outcome data.

The mean grayscale signal intensity (SI) and standard deviation (SD) for normal LV myocardium were measured for each patient, with a region of interest placed in a portion of nulled myocardium (i.e., without LGE on visual inspection).

In order to identify the best SI threshold of scar detection as well as HSA, scar size was determined using a threshold of 4 or $6 \mathrm{SD}$ above the mean of the remote normal myocardium and by manual tracing (Figure 1); HSA was defined as the difference between 2 SD and 4 $\mathrm{SD}\left(\mathrm{HSA}_{2-4 \mathrm{SD}}\right)$, between $2 \mathrm{SD}$ and $6 \mathrm{SD}\left(\mathrm{HSA}_{2-6 \mathrm{SD}}\right)$ and between $4 \mathrm{SD}$ and $6 \mathrm{SD}$ ( $\left.\mathrm{HSA}_{4-6 \mathrm{SD}}\right)$. The amount of LGE for each group was expressed in grams.

\section{ICD implantation and follow-up}

All devices were implanted using standard surgical technique; choice of device was at the discretion of the implanting physician and the device was activated at completion of implantation.

All devices were programmed for both anti-tachycardial pacing (ATP) and shock with three zones of therapy including shock for ventricular fibrillation (VF), ATP followed by shock for fast VT, and a monitored zone for slower VT. Exact therapy settings were adjusted at the discretion of the implanting physician.

Devices were interrogated at 1 and 3 months after implantation and every 6 months thereafter in the device clinic. During regular follow-ups in the device clinic 

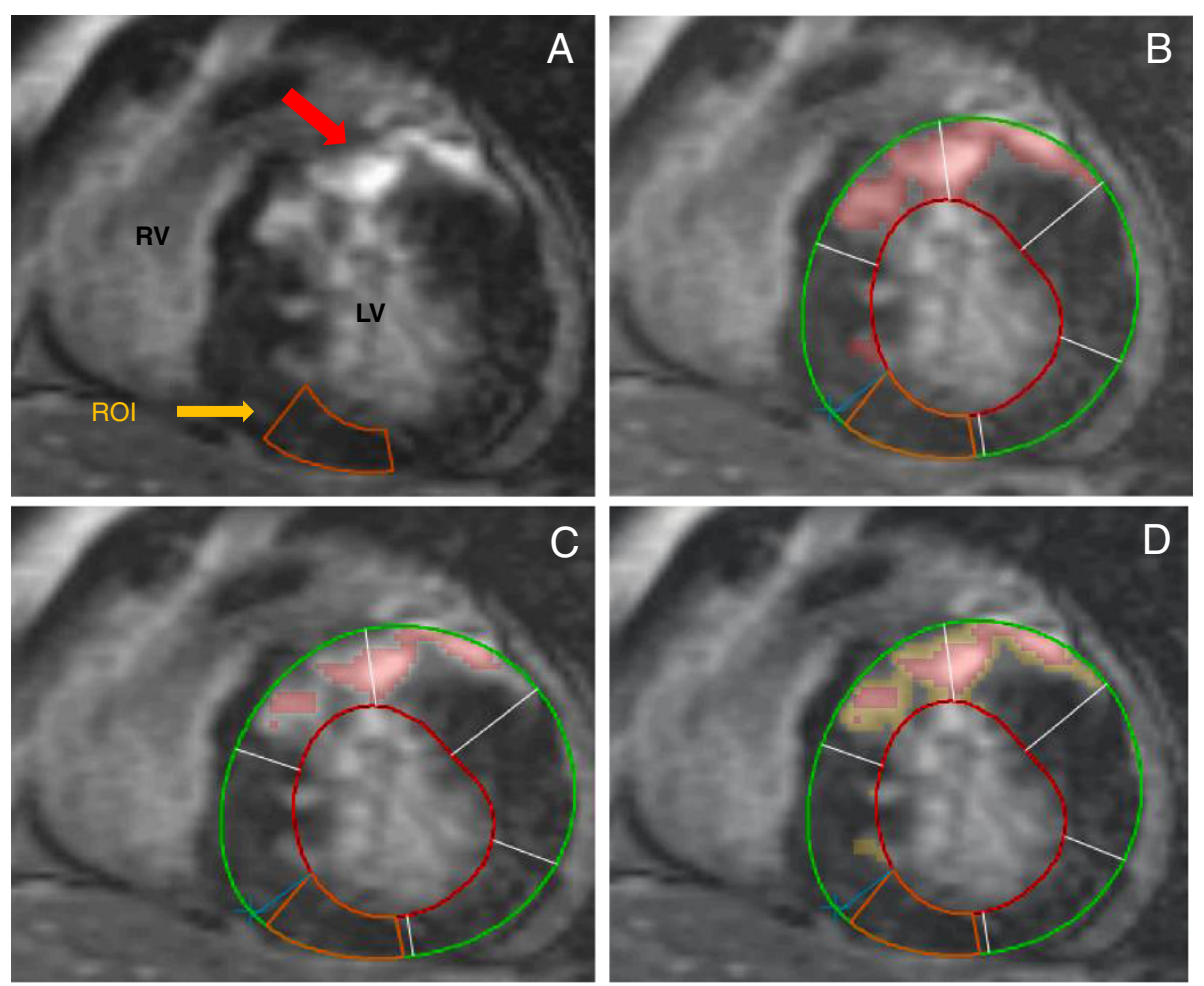

Figure 1 Assessment of heterogeneous scar area (HSA). A) Mid-ventricular short axis LGE image of a patient with considerable LGE (red arrow) in ventricular septum and anterior wall, and a region of interest in normal myocardium in the inferior wall (ROl; orange box) used to define thresholds for LGE. RV indicates right ventricle; LV, left ventricle. B) Endocardial (red) and epicardial (green) borders were outlined manually. Grayscale threshold 2SDs above the mean signal intensity of the ROI (red shading) was outlined. C) Grayscale threshold 4SDs above the

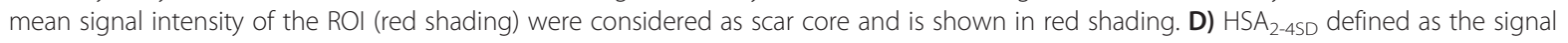
intensity between $\geq 2 S D$ and $<4 S D$ is shown in yellow shading, superimposed on scar core (>4SD) in red shading.

appropriate sensing was confirmed for all patients; the device was interrogated, and recorded events and ICD therapy reviewed. Stored electrograms prior to device therapy were assessed by an experienced cardiologist blinded to CMR findings. Appropriate ICD therapy was defined as antitachycardia pacing or shocks delivered for ventricular tachyarrhythmias [17-20].

\section{Statistics}

Continuous variables are presented as mean \pm SD. Categorical variables are presented in number and percentage. Pre-ICD implantation NYHA class is presented in median \pm interquartile range of $25-75 \%$. Survival time for appropriate ICD therapy outcome was defined to be the time (number of days) from ICD implantation to the appropriate ICD therapy. The end of the follow-up period was September 30, 2011. If the patient did not have an appropriate ICD therapy in the follow-up period, then the patient's outcome was considered to be censored. Univariate Cox regression analysis was utilized to assess the association between each variable and the survival function of appropriate ICD therapy. A correlation matrix was made to assess the association among the predictors. Statistically significant variables from the univariate analysis were identified and entered into the Cox's multivariable model as exploratory analysis only, due to the limited number of events. Variables such as $\mathrm{HSA}_{2-4 \mathrm{SD}}$ and $\mathrm{HSA}_{4-6 \mathrm{SD}}$ were both significant but were highly correlated; therefore, only one was entered into the multivariate model ( $\mathrm{HSA}_{2-4 \mathrm{SD}}$ was more significant). Since $\mathrm{HSA}_{2-4 \mathrm{SD}}$ was found to be an independent predictor of appropriate ICD therapy, the study population was divided into 2 groups based on the median value of the $\mathrm{HSA}_{2-4 \mathrm{SD}}(5.9 \mathrm{~g})$, and the event-rate of both cohorts was further analyzed by the method of Kaplan-Meier. The log-rank test was used to compare Kaplan-Meier survival curve. All statistical analyses were performed using SAS (v9.2, SAS Institute, Cary, NC). A P value of $<0.05$ was considered to be significant.

\section{Results}

\section{Clinical and demographic data}

A total of 41 patients who were referred for ICD implantation as the primary prevention of SCD and had a pre-ICD implantation LGE-CMR available, were identified. Baseline characteristics of the entire cohort are 
summarized in Table 1. One patient had a complicated ICD implantation which led to non-arrhythmic death 2 days after the procedure and was excluded from analysis. During the $25 \pm 24$ months follow-up, 4 patients died. Primary indication for cardiac MRI was assessment of cardiomyopathy (9 patients), LV and RV function (5 patients), and viability and scar assessment (26 patients).

\section{ICD follow-up data}

After a mean follow-up of $25 \pm 24$ months (median $=13$, IQR: 7-35 months), appropriate ICD therapy occurred in $7(17.5 \%)$ patients including 2 patients who received ATP and 5 patients who received ICD shocks. One of the patients with ICD discharge underwent VT ablation. Two patients in the group without ICD therapy received inappropriate shocks for atrial fibrillation.

\section{CMR data}

Data from LGE-CMR and function analysis are summarized in Table 2. There was a trend for greater scar size in the appropriate ICD therapy group by the $4 \mathrm{SD}$ $(P=0.11)$ and 6 SD $(P=0.19)$ definitions. HSA was significantly greater in the appropriate ICD therapy group $\left(\mathrm{HSA}_{2-4 \mathrm{SD}}, \mathrm{P}=0.001\right.$; $\mathrm{HSA}_{4-6 \mathrm{SD}}, \mathrm{P}=0.03$ ) (Table 2).

LVEF was also lower in the appropriate ICD therapy group $(\mathrm{P}=0.04)$. The other functional and volumetric measurements were comparable between 2 groups (Table 2).

Table 1 Patients demographics

\begin{tabular}{|c|c|c|c|}
\hline & $\begin{array}{c}\text { Appropriate ICD } \\
\text { therapy } \\
n=7\end{array}$ & $\begin{array}{l}\text { No appropriate } \\
\text { ICD therapy } \\
\text { n }=33\end{array}$ & P-value* \\
\hline Age (year) & $66 \pm 10$ & $61 \pm 11$ & 0.824 \\
\hline $\operatorname{Sex}(M), n(\%)$ & $6(86)$ & $23(70)$ & 0.323 \\
\hline ICM, n (\%) & $5(71)$ & $15(45)$ & 0.427 \\
\hline $\mathrm{BiV}, \mathrm{n}(\%)$ & $2(28)$ & $9(27)$ & 0.729 \\
\hline Diabetes, n (\%) & $5(71)$ & $9(27)$ & $0.081 \#$ \\
\hline Hypertension, n (\%) & $6(86)$ & $24(72)$ & 0.819 \\
\hline Dyslipidemia, n (\%) & $3(43)$ & 18(54) & 0.233 \\
\hline Beta-blocker, n (\%) & $5(71)$ & $30(91)$ & 0.453 \\
\hline ACE-inhibitor, n (\%) & $7(100)$ & $31(94)$ & 0.996 \\
\hline Anti-arrhythmic, n (\%) & 0 & $2(6)$ & 0.995 \\
\hline Aspirin, n (\%) & $5(71)$ & $26(79)$ & 0.493 \\
\hline Pre-ICD NYHA & $3 \pm 1$ & $3 \pm 1$ & 0.810 \\
\hline $\begin{array}{l}\text { Inappropriate ICD } \\
\text { therapy }\end{array}$ & 0 & $2(6)$ & 0.996 \\
\hline \multicolumn{4}{|c|}{$\begin{array}{l}\text { BiV: Biventricular pacemaker; ICM: ischemic cardiomyopathy; ACE: } \\
\text { converting enzyme; Echo: echocardiography; NYHA: new york } \\
\text { heart association. } \\
\text { * Univariate Cox's proportional hazard model. } \\
\text { \# was considered clinically significant and was entered into the } \\
\text { multivar model. }\end{array}$} \\
\hline
\end{tabular}

Table 2 CMR measurements

\begin{tabular}{|c|c|c|c|}
\hline & $\begin{array}{c}\text { Appropriate } \\
\text { ICD therapy } \\
n=7\end{array}$ & $\begin{array}{l}\text { No appropriate } \\
\text { ICD therapy } \\
n=33\end{array}$ & P-value* \\
\hline LVM (g) & $173 \pm 30$ & $160 \pm 47$ & 0.599 \\
\hline LVMI (g/m2) & $91 \pm 14$ & $82 \pm 20$ & 0.369 \\
\hline LVEF (\%) & $23 \pm 6.5$ & $31 \pm 9$ & 0.04 \\
\hline LVEDV (ml) & $263 \pm 34$ & $268 \pm 107$ & 0.831 \\
\hline LVEDVI (ml/m2) & $140 \pm 29$ & $137 \pm 45$ & 0.559 \\
\hline LVESV (ml) & $202 \pm 35$ & $195 \pm 93$ & 0.546 \\
\hline RVEDV (ml) & $128 \pm 19$ & $160 \pm 71$ & 0.369 \\
\hline RVEDVI (ml/m2) & $69 \pm 12$ & $78 \pm 20$ & 0.443 \\
\hline RVESV (ml) & $66 \pm 5.5$ & $77 \pm 41$ & 0.719 \\
\hline RVEF (\%) & $48 \pm 8$ & $51 \pm 12$ & 0.332 \\
\hline LGE presence (\%) & $6(86)$ & $19(57)$ & 0.155 \\
\hline LGE4SD (g) & $44 \pm 29$ & $27 \pm 31$ & 0.112 \\
\hline LGE6SD (g) & $32 \pm 25$ & $21 \pm 27$ & 0.193 \\
\hline Visual (g) & $34 \pm 23$ & $24 \pm 28$ & 0.245 \\
\hline HSA2-4SD (g) & $17 \pm 12$ & $5 \pm 7$ & 0.001 \\
\hline HSA4-6SD (g) & $11 \pm 10$ & $5 \pm 7$ & 0.038 \\
\hline
\end{tabular}

LVM:Left ventricular mass; LVMI:left ventricular mass index; LVEDV:left ventricular end-diastolic volume; LVEDVI:left ventricular end-diastolic volume index; LVESV:left ventricular end-systolic volume; RVEDV:right ventricular enddiastolic volume; RVEDVI:right ventricular end-diastolic volume index; RVESV: left ventricular end-systolic volume; RVEF:right ventricular ejection fraction; LGE: late gadolinium enhancement; HSA:heterogenous scar area. * Univariate Cox's proportional hazard model.

\# HSA2-4SD and HSA4-6SD were highly correlated ( $r=0.69$, $p$-value: 0.0001 ), so only HSA2-4SD was entered into the multivariate model.

Univariate analysis showed a significant relationship between HSA and ICD therapy, whether it is defined by $\mathrm{HSA}_{2-4 \mathrm{SD}}$ (HR 1.11, chi-square $=10.73, \mathrm{p}=0.001$ ), $\mathrm{HSA}_{4-6 \mathrm{SD}}$ (HR 1.09, chi-square $\left.=4.28, \mathrm{p}=0.039\right)$, or $\mathrm{HSA}_{2-6 \mathrm{SD}}(\mathrm{HR}$ 1.6, chi-square $=9.09, \mathrm{p}-0.003)$. Due to the limited number of events, a multivariable Cox model was constructed as exploratory analysis to control for the possible confounding effects of LVEF and diabetes on the relationship between $\mathrm{HSA}_{2-4 \mathrm{SD}}$ and ICD therapy. $\mathrm{HSA}_{2-4 \mathrm{SD}}\left(\mathrm{HR}_{\text {adjusted }} 1.08,95 \% \mathrm{CI}\right.$ : $1.00-1.16$, $\mathrm{P}=0.04$ ) remained a significant predictor of ICD therapy (Table 3), suggesting that for each gram increase in the $\mathrm{HSA}_{2-4 \mathrm{SD}}$, there is an $8 \%$ increase in the risk of appropriate ICD therapy.

Table 3 Multivariate Cox proportional hazard regression

\begin{tabular}{lccc}
\hline & HR & $\mathbf{9 5 \% ~ C l}$ & P-value \\
\hline CMR-LVEF (\%) & 0.95 & $0.84-1.07$ & 0.409 \\
DM & 2.61 & $0.39-17.49$ & 0.321 \\
HSA2-4SD (gr) & 1.08 & $1.00-1.16$ & 0.041
\end{tabular}

DM:diabetes mellitus; HSA:hetreogenous scar area; HR: hazard ratio. 
Kaplan-Meier analysis (Figure 2) showed that patients with $\mathrm{HSA}_{2-4 \mathrm{SD}}$ greater than the median (5.9 grams) had a lower survival free of appropriate ICD therapy $(\mathrm{P}=0.026)$.

\section{Discussion}

In this retrospective study of patients with ischemic and non-ischemic cardiomyopathy undergoing a CMR study prior to ICD implantation for primary prevention of $\mathrm{SCD}$, we found that scar heterogeneity identified a subset of patients who subsequently had appropriate ICD therapy. Our data also showed a trend for LGE-CMR scar size as a predictor for ICD therapy. Additionally, in multivariate analysis, HSA was the only independent predictor which had significant impact on appropriate ICD therapy, while LVEF did not.

Current guidelines recommend ICD implantation for primary prevention of SCD based on LVEF thresholds $[3,4,21]$. Based on this metric, a large number of patients become eligible for this expensive treatment, but in a majority of patients receiving ICDs for primary prevention of SCD, appropriate ICD therapy does not occur during reported follow-up times [5]. Thus, there is a growing effort to better risk stratify patients with reduced LVEF most likely to benefit from prophylactic ICD implantation $[6,7]$.

The major cause of SCD is ventricular tachyarrhythmia including VT and VF. Re-entry circuits appear to be a common mechanism underlying these ventricular arrhythmias [22] and the presence of myocardial scar

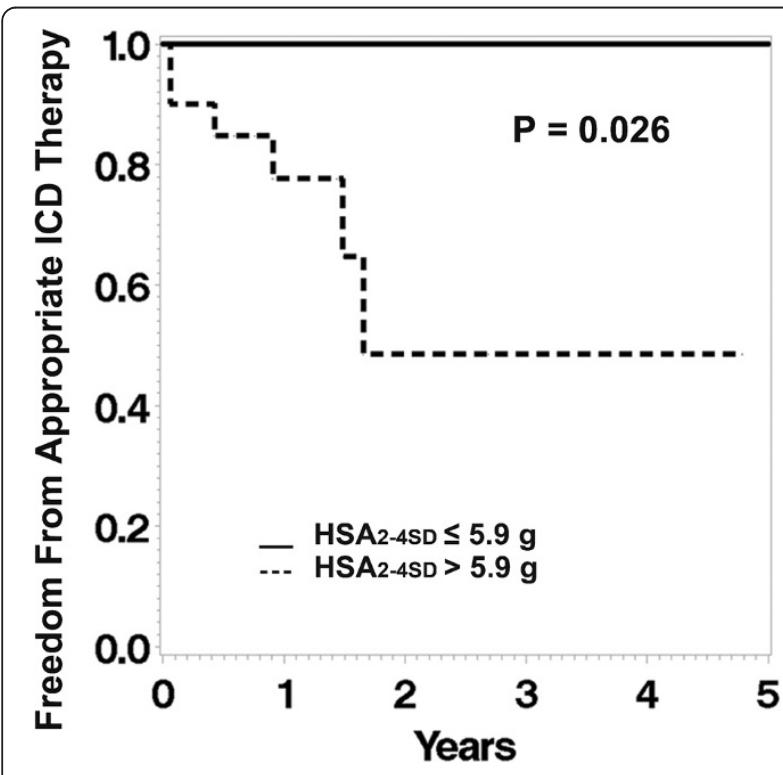

Figure 2 Kaplan-Meier analysis shows that patients with $\mathrm{HSA}_{2-4 S \mathrm{D}}$ greater than the median (5.9 grams) had lower survival free of appropriate ICD therapy (dashed line) whereas the patients with smaller $\mathrm{HSA}_{2-4 S D}(\leq \mathbf{5} .9$ grams) had higher longer survival free of ICD firing (solid line). has been indentified to be linked to the development of re-entrant arrhythmias [22,23]. LGE-CMR allows us to delineate myocardial fibrosis and scar tissue [24,25].

LGE presence has been shown to correlate with ventricular arrhythmia and ICD therapy in ischemic and non-ischemic cardiomyopathies [12]. In our study, the presence of scar was seen more frequently in patients requiring appropriate ICD therapy. However, 57\% of patients who did not have ICD therapy had LGE.

In previous studies it has been shown that scar size in LGE-CMR [26] or in combination with electroanatomical mapping [27] can predict ventricular arrhythmia in patients with cardiomyopathy. Our data demonstrate not only that the extent of myocardial scar by different definitions (4SD, 6SD and visual thresholds) was larger in the appropriate ICD therapy group, but also the heterogeneity of scar is an independent predictor of appropriate ICD therapy. In previous studies, it has been reported that the extent of LV scar as well as peri-infarct zone were independent predictors of VT inducibility $[15,28]$.

The partial volume effect is defined as an admixture of both infarcted (high SI) and noninfarcted (low SI) tissue. With averaging the 2 different SIs will be averaged, and those particular voxels will be represented by an intermediate SI (gray), affecting the HSA detection and measurement. The partial volume effect could result from volume-averaging effects of an area of uniformly fibrotic tissue (dense infarct scar) with an adjacent area of preserved, viable myocardium, particularly in situations in which spatial resolution is limited $[24,28,29]$. In this case, anatomically, there would be a narrow border between fibrotic scar and viable myocardium, and the limited spatial resolution would render an apparent intermediate SI in that border region. Partial volume effects due to averaging of normal and necrotic tissue have been demonstrated by LGE-CMR in experimental animal studies [24,29-31]. However, a second explanation is that the gray zone arises from the intermingling of preserved myocardium with bundles of fibrotic, infarcted scar within the same voxel. In this case, there would be a more gradual anatomic transition from dense, infarct core to preserved tissue beyond the infarct periphery. The latter mechanism is supported by pathological data [32,33].

We also wish to emphasize that having lower HSA does not invalidate previous risk stratification strategies based on other clinical factors. Decisions to exclude patients from receiving an ICD should not be based solely on HSA quantification, particularly in patients already deemed high risk prior to their CMR.

Our data in this study agree with previous studies. Schmidt and colleagues [15] studied 47 patients with a prior MI who underwent ICD implantation. They reported that infarct tissue heterogeneity was strongly 
associated with inducibility for monomorphic ventricular tachycardia, and was the single significant factor in a stepwise logistic regression.

To our knowledge, our study has the longest follow-up time and includes patients over a long time period from 2003 to 2011 which makes it unique among similar studies. Although some other studies have looked into a similar hypothesis, they all had a shorter follow-up time. Roes et al. showed that after a mean follow-up of 8.5 months, infarct gray zone was the strongest predictor of appropriate ICD therapy in patients with prior MI [34]. In addition, we have defined infarct heterogeneity by two different criteria to find the best metric that correlates well with appropriate ICD therapy. Scott et al. reported that during 19 months of follow-up of patients with coronary artery disease, appropriate ICD therapy occurred in patients with a greater scar size [35]. Iles et al. studied patients with cardiomyopathy and found that during 18 months of follow-up appropriate ICD therapy occurred more frequently in patients with LGE [12]. Compared to previous studies, which have mainly included ischemic populations, we have enrolled those with ischemic and non-ischemic cardiomyopathy.

A number of limitations of the current study need to be addressed. First, this study is a single center retrospective cohort and the results should be supported by a prospective multicenter trial. Second, the small sample size in this study prevented us from entering more variables into multivariable model, some of which may have potential confounding effects. Furthermore, the presented multivariable model is intended to be exploratory in nature, rather than demonstrating the independent relationship between HSA and ICD therapy. Also, most of the patients with appropriate ICD therapy had ischemic cardiomyopathy (71\%). The sample size of the current study does not allow to study the value of LGECMR in CAD versus non-CAD patients. Thus, it is necessary to conduct a large trial in order to confirm the results of our study. In several patients with diffuse LGE in multiple regions of the myocardium, it was challenging to demarcate a region of interest (ROI) to define normal myocardium. However, great care was made to exclude regions of LGE and blood pool in the ROI, and all regions subsequently assigned as scar were verified visually before proceeding. In our study, 9 patients had 3D PSIR LGE images which were different from 2D LGE images. Despite this difference, we did not notice any difference in the result by excluding this subset of patients, presumably due to small size.

\section{Conclusions}

In conclusion, LGE-CMR scar tissue heterogeneity is an important parameter for risk stratification of patients being considered for primary prevention ICD implantation. If supported by prospective, multicenter trials, LGE-CMR may emerge as the imaging metric for risk stratification for primary prevention ICD implantation.

\section{Competing interests}

The authors declare that they have no competing interests.

\section{Authors' contributions}

HR: Conception and design, data extraction, analysis and interpretation of data, statistical analysis, drafting of the manuscript; AT: ICD data extraction; RHC: analysis and interpretation of data, statistical analysis, drafting of the manuscript SJP: ICD data extraction, THH: analysis and interpretation of data $\mathrm{LN}$ : analysis and interpretation of data, JLS: data extraction, SNH: data extraction, PJZ: Conception and design, AEB: Conception and design, interpretation of data, drafting of manuscript, MEJ: Conception and design, interpretation of data, drafting of manuscript, WJM: Conception and design, interpretation of data, drafting of the manuscript, RN: Conception and design, analysis and interpretation of data, drafting of the manuscript; All authors have given approval of this manuscript for publication.

\section{Acknowledgement}

This study is supported by NIH R01EB008743-01 and 1 UL1 RR025758-01 from the National Center for Research Resources to support the Harvard Clinical and Translational Science Center.

\section{Author details}

${ }^{1}$ Department of Medicine, Boston, MA, USA. ${ }^{2}$ Radiology, Beth Israel Deaconess Medical Center and Harvard Medical School, Boston, MA, USA. ${ }^{3}$ Beth Israel Deaconess Medical Center, 330 Brookline Ave, Boston, MA 02215, USA.

Received: 24 October 2012 Accepted: 8 March 2013

Published: 10 April 2013

\section{References}

1. Chugh SS, Jui J, Gunson K, Stecker EC, John BT, Thompson B, llias N, Vickers C, Dogra V, Daya M, et al. Current burden of sudden cardiac death: multiple source surveillance versus retrospective death certificate-based review in a large U.S. community. J Am Coll Cardiol. 2004; 44:1268-75.

2. Kadish A, Dyer A, Daubert JP, Quigg R, Estes NAM, Anderson KP, Calkins H, Hoch D, Goldberger J, Shalaby A, et al. Prophylactic Defibrillator Implantation in Patients with Nonischemic Dilated Cardiomyopathy. New England Journal of Medicine. 2004; 350:2151-8.

3. Bardy $\mathrm{GH}$, Lee $\mathrm{KL}$, Mark DB, Poole JE, Packer DL, Boineau R, Domanski M, Troutman C, Anderson J, Johnson G, et al. Amiodarone or an implantable cardioverter-defibrillator for congestive heart failure. N Engl J Med. 2005; 352:225-37.

4. Epstein $A E$, DiMarco JP, Ellenbogen KA, Estes NA 3rd, Freedman RA, Gettes LS, Gillinov AM, Gregoratos G, Hammill SC, Hayes DL, et al. ACC/AHA/HRS 2008 Guidelines for Device-Based Therapy of Cardiac Rhythm Abnormalities: a report of the American College of Cardiology/American Heart Association Task Force on Practice Guidelines (Writing Committee to Revise the ACC/AHA/NASPE 2002 Guideline Update for Implantation of Cardiac Pacemakers and Antiarrhythmia Devices): developed in collaboration with the American Association for Thoracic Surgery and Society of Thoracic Surgeons. Circulation. 2008; 117:e350-408.

5. Bardy GH, Lee KL, Mark DB, Poole JE, Packer DL, Boineau R, Domanski M, Troutman C, Anderson J, Johnson G, et al. Amiodarone or an Implantable Cardioverter-Defibrillator for Congestive Heart Failure. New Engl J Med. 2005; 352:225-37.

6. Buxton AE, Lee KL, Hafley GE, Pires LA, Fisher JD, Gold MR, Josephson ME, Lehmann MH, Prystowsky EN. Limitations of Ejection Fraction for Prediction of Sudden Death Risk in Patients With Coronary Artery Disease: Lessons From the MUSTT Study. J Am Coll Cardiol. 2007; 50:1150-7.

7. Buxton AE, Sweeney MO, Wathen MS, Josephson ME, Otterness MF, HoganMiller E, Stark AJ, Degroot PJ. QRS duration does not predict occurrence of ventricular tachyarrhythmias in patients with implanted cardioverterdefibrillators. J Am Coll Cardiol. 2005; 46:310-6.

8. Zimetbaum PJ, Buxton AE, Batsford W, Fisher JD, Hafley GE, Lee KL, O'Toole MF, Page RL, Reynolds M, Josephson ME. Electrocardiographic predictors 
of arrhythmic death and total mortality in the multicenter unsustained tachycardia trial. Circulation. 2004; 110:766-9.

9. Hsia HH, Marchlinski FE. Characterization of the electroanatomic substrate for monomorphic ventricular tachycardia in patients with nonischemic cardiomyopathy. Pacing Clin Electrophysiol. 2002; 25:1114-27.

10. Wu TJ, Ong JJ, Hwang C, Lee JJ, Fishbein MC, Czer L, Trento A, Blanche C, Kass RM, Mandel WJ, et al. Characteristics of wave fronts during ventricular fibrillation in human hearts with dilated cardiomyopathy: role of increased fibrosis in the generation of reentry. J Am Coll Cardiol. 1998; 32:187-96.

11. Nazarian S, Bluemke DA, Lardo AC, Zviman MM, Watkins SP, Dickfeld TL, Meininger GR, Roguin A, Calkins H, Tomaselli GF, et al. Magnetic resonance assessment of the substrate for inducible ventricular tachycardia in nonischemic cardiomyopathy. Circulation. 2005; 112:2821-5.

12. Iles L, Pfluger H, Lefkovits L, Butler MJ, Kistler PM, Kaye DM, Taylor AJ. Myocardial fibrosis predicts appropriate device therapy in patients with implantable cardioverter-defibrillators for primary prevention of sudden cardiac death. J Am Coll Cardiol. 2011; 57:821-8.

13. Wu E, Judd RM, Vargas JD, Klocke FJ, Bonow RO, Kim RJ. Visualisation of presence, location, and transmural extent of healed Q-wave and non-Q-wave myocardial infarction. Lancet. 2001; 357:21-8.

14. Mahrholdt H, Wagner A, Holly TA, Elliott MD, Bonow RO, Kim RJ, Judd RM. Reproducibility of chronic infarct size measurement by contrastenhanced magnetic resonance imaging. Circulation. 2002; 106:2322-7.

15. Schmidt A, Azevedo CF, Cheng A, Gupta SN, Bluemke DA, Foo TK, Gerstenblith G, Weiss RG, Marban E, Tomaselli GF, et al. Infarct tissue heterogeneity by magnetic resonance imaging identifies enhanced cardiac arrhythmia susceptibility in patients with left ventricular dysfunction. Circulation. 2007; 115:2006-14.

16. Grothues F, Smith GC, Moon JC, Bellenger NG, Collins P, Klein HU, Pennell DJ. Comparison of interstudy reproducibility of cardiovascular magnetic resonance with two-dimensional echocardiography in normal subjects and in patients with heart failure or left ventricular hypertrophy. Am J Cardiol. 2002; 90:29-34.

17. Grimm W, Hoffmann JJ, Muller HH, Maisch B. Implantable defibrillator event rates in patients with idiopathic dilated cardiomyopathy, nonsustained ventricular tachycardia on Holter and a left ventricular ejection fraction below 30\%. J Am Coll Cardiol. 2002; 39:780-7.

18. Hook BG, Marchlinski FE. Value of ventricular electrogram recordings in the diagnosis of arrhythmias precipitating electrical device shock therapy. J Am Coll Cardiol. 1991; 17:985-90.

19. Marchlinski FE, Gottlieb CD, Sarter B, Finkle J, Hook B, Callans D, Schwartzman D. ICD data storage: value in arrhythmia management. Pacing Clin Electrophysiol. 1993; 16:527-34.

20. Callans DJ, Hook BG, Marchlinski FE. Use of bipolar recordings from patchpatch and rate sensing leads to distinguish ventricular tachycardia from supraventricular rhythms in patients with implantable cardioverter defibrillators. Pacing Clin Electrophysiol. 1991; 14:1917-22.

21. Moss AJ, Zareba W, Hall WJ, Klein H, Wilber DJ, Cannom DS, Daubert JP, Higgins SL, Brown MW, Andrews ML. Prophylactic Implantation of a Defibrillator in Patients with Myocardial Infarction and Reduced Ejection Fraction. New Engl J Med. 2002; 346:877-83.

22. Stevenson WG, Friedman PL, Sager PT, Saxon LA, Kocovic D, Harada T, Wiener I, Khan H. Exploring postinfarction reentrant ventricular tachycardia with entrainment mapping. J Am Coll Cardiol. 1997; 29:1180-9.

23. Zipes DP, Wellens HJ. Sudden cardiac death. Circulation. 1998; 98:2334-51.

24. Kim RJ, Fieno DS, Parrish TB, Harris K, Chen EL, Simonetti O, Bundy J, Finn JP, Klocke FJ, Judd RM. Relationship of MRI delayed contrast enhancement to irreversible injury, infarct age, and contractile function. Circulation. 1999; 100:1992-2002.

25. Kim WY, Danias PG, Stuber M, Flamm SD, Plein S, Nagel E, Langerak SE, Weber OM, Pedersen EM, Schmidt M, et al. Coronary magnetic resonance angiography for the detection of coronary stenoses. N Engl J Med. 2001; 345:1863-9.

26. de Haan S, Meijers TA, Knaapen P, Beek AM, van Rossum AC, Allaart CP. Scar size and characteristics assessed by CMR predict ventricular arrhythmias in ischaemic cardiomyopathy: comparison of previously validated models. Heart. 2011.

27. Crawford T, Cowger J, Desjardins B, Kim HM, Good E, Jongnarangsin K, Ora H, Chugh A, Pelosi F, Morady F, Bogun F. Determinants of postinfarction ventricular tachycardia. Circ Arrhythm Electrophysiol. 2010; 3:624-31.
28. Bello D, Fieno DS, Kim RJ, Pereles FS, Passman R, Song G, Kadish AH, Goldberger JJ. Infarct morphology identifies patients with substrate for sustained ventricular tachycardia. J Am Coll Cardiol. 2005; 45:1104-08.

29. Klocke FJ, Wu E, Lee DC. "Shades of gray" in cardiac magnetic resonance images of infarcted myocardium: can they tell us what we'd like them to? Circulation. 2006; 114:8-10.

30. Hsu LY, Natanzon A, Kellman P, Hirsch GA, Aletras AH, Arai AE. Quantitative myocardial infarction on delayed enhancement MRI. Part I: Animal validation of an automated feature analysis and combined thresholding infarct sizing algorithm. J Magn Reson Imaging. 2006; 23:298-308.

31. Schelbert EB, Hsu LY, Anderson SA, Mohanty BD, Karim SM, Kellman P, Aletras AH, Arai AE. Late gadolinium-enhancement cardiac magnetic resonance identifies postinfarction myocardial fibrosis and the border zone at the near cellular level in ex vivo rat heart. Circ Cardiovasc Imaging. 2010; 3:743-52.

32. Deneke T, Muller KM, Lemke B, Lawo T, Calcum B, Helwing M, Mugge A, Grewe PH. Human histopathology of electroanatomic mapping after cooled-tip radiofrequency ablation to treat ventricular tachycardia in remote myocardial infarction. J Cardiovasc Electrophysiol. 2005; 16:1246-51.

33. Freeman I, Grunwald AM, Robin B, Rao PS, Bodenheimer MM. Effect of early reperfusion on use of triphenyltetrazolium chloride to differentiate viable from non-viable myocardium in area of risk. Cardiovasc Res. 1990; 24:109-14.

34. Roes SD, Borleffs CJ, van der Geest RJ, Westenberg JJ, Marsan NA, Kaandorp TA, Reiber JH, Zeppenfeld K, Lamb HJ, de Roos A, et al. Infarct tissue heterogeneity assessed with contrast-enhanced MRI predicts spontaneous ventricular arrhythmia in patients with ischemic cardiomyopathy and implantable cardioverter-defibrillator. Circ Cardiovasc Imaging. 2009; 2:183-90.

35. Scott PA, Morgan JM, Carroll N, Murday DC, Roberts PR, Peebles CR, Harden SP, Curzen NP. The Extent of Left Ventricular Scar Quantified by Late Gadolinium Enhancement MRI Is Associated with Spontaneous Ventricular Arrhythmias in Patients with Coronary Artery Disease and Implantable Cardioverter Defibrillators. Circ Arrhythm Electrophysiol. 2011.

doi:10.1186/1532-429X-15-31

Cite this article as: Rayatzadeh et al.: Scar heterogeneity on cardiovascular magnetic resonance as a predictor of appropriate implantable cardioverter defibrillator therapy. Journal of Cardiovascular Magnetic Resonance 2013 15:31.

\section{Submit your next manuscript to BioMed Central and take full advantage of:}

- Convenient online submission

- Thorough peer review

- No space constraints or color figure charges

- Immediate publication on acceptance

- Inclusion in PubMed, CAS, Scopus and Google Scholar

- Research which is freely available for redistribution 